\title{
«SIETE PLANETAS REALES»: EL DISEÑO POLÍTICO DE FERNANDO DE ANTEQUERA EN UNA COMPOSICIÓN DEL CANCIONERO DE BAENA (N. 514, ID 1640)*
}

\author{
Isabella Proia \\ Sapienza, Università di Roma
}

En los cancioneros compilados en el entorno cortesano de Castilla y Aragón a lo largo del siglo XV se reflejan a menudo los acontecimientos políticos impulsados, sobre todo a partir de la segunda década del siglo, por la ambiciosa acción de Fernando de Antequera y de sus hijos, los llamados «Infantes de Aragón». En esta producción no faltan poemas pertenecientes al género de la profecía, cuyo objetivo era la glorificación dinástica y la propaganda política a favor de Fernando de Antequera y de sus hijos. Quisiera examinar, en particular, las relaciones que se dibujan entre literatura y poder en la producción poética del franciscano Diego de Valencia de León, autor de un panegírico a los siete hijos de Fernando de Antequera recogido en el Cancionero de Baena bajo el número 514. A partir del análisis textual se intentará, además, precisar las posibles fechas de redacción del poema.

\section{Fernando de Antequera y sus hijos, los «Infantes de Aragón»}

Entre la segunda mitad del siglo XIV y la primera mitad del siglo XV se registró un notable incremento en los contactos culturales entre los reinos de Castilla y Aragón: esta tendencia, que empezó a manifestarse en las últimas décadas del siglo XIV con el despertar cultural que siguió al período de las guerras civiles en Castilla, se intensificó luego, especialmente en lo que concierne a la producción poética, en la década de la regencia de Fernando de Antequera (1406-1416). Hijo segundón del rey de Castilla Juan I y de Leonor de Aragón, Fernando sería el primer Trastámara en subir al trono aragonés gracias al compromiso de Caspe, que en 1412 puso fin a la crisis dinástica

${ }^{*}$ Este trabajo se enmarca en el Proyecto FIRB - Futuro in ricerca (RBFR10102K004) «Repertorio ipertestuale della Tradizione lirica romanza delle Origini» (TraLiRO), coordinado por Alessio Decaria. 
causada por la muerte sin descendientes de Martín I «el Humano». Por otra parte, aun siendo el segundo hijo de Juan I, Fernando también aspiraba a heredar el trono de Castilla, en virtud de la débil salud de su hermano mayor, el rey Enrique III; sin embargo, en 1405, el nacimiento de Juan, el único hijo varón de Enrique «el doliente», puso fin a sus esperanzas de llegar a ser monarca castellano. De todas formas fue tutor y corregente de su sobrino Juan junto con la madre de él, Catalina de Lancaster. Durante la regencia, protagonizó la iniciativa militar para la reconquista del reino de Granada que culminaría en la gloriosa toma de Antequera, que le valdría su célebre apodo.

Cuando fue coronado Rey de Aragón a raíz del compromiso de Caspe ${ }^{1}$, Fernando era ya padre de siete hijos, todos nacidos y educados en Castilla y allí fuertemente afincados. Sin embargo, sus destinos se vincularían muy pronto a los demás reinos peninsulares: en primer lugar el de Aragón, y luego los reinos de Navarra y Portugal gracias a la inteligente política matrimonial tenazmente perseguida por Fernando con el fin de dotar a todos sus vástagos de unos patrimonios personales adecuados al destino real que deseaba para cada uno de ellos. Después de Caspe, sus hijos accedieron al título de Infantes: de allí en adelante fueron los «Infantes de Aragón», y así los llamaron siempre los cronistas, pese a su origen y ascendencia netamente castellana. La definición de «Infantes de Aragón», también inmortalizada por los célebres versos de Jorge Manrique ${ }^{2}$, no deja de hacer pensar en la leyenda de los Infantes de Lara. Por supuesto, el paralelismo ${ }^{3}$ entre los Infantes de Aragón y los de Lara, pertenecientes tanto los primeros como los segundos a la rama

\footnotetext{
${ }^{1}$ Sobre el compromiso de Caspe ver Ramón Menéndez Pidal, «El compromiso de Caspe. Autodeterminación de un pueblo (1410-1412)», en Historia de España, dir. Ramón Menéndez Pidal, 26 vols. Madrid, Espasa-Calpe, 1952-1992, vol. XV, 1964; Ferran Soldevila, El compromis de Casp (Resposta al Sr. Menéndez Pidal), Barcelona, Dalmau, 1965; Manuel Dualde Serrano y José Camarena Mahiques, El compromiso de Caspe, Zaragoza, Institución Fernando el Católico, 1971; Jaime Vicens Vives, Els Trastàmares, Barcelona, Teide, 1956.

${ }^{2}$ Ver los vv. 181-192 de las Coplas a la muerte de su padre: «¿Qué se hizo el Rey Don Juan?, / los Infantes de Aragón, /¿qué se hizieron? /¿Qué fue de tanto galán? / ¿Qué fue de tanta invención / como traxieron? / Las justas y los torneos, / paramentos, bordaduras / y cimeras / ¿fueron sino devaneos? / ¿Qué fueron sino verduras / de las heras?» (se cita por la edición incluida en Vicenç Beltran, Poesía cortesana. Siglo Xv. Rodrigo Manrique, Gómez Manrique, Jorge Manrique, Madrid, Fundación José Antonio de Castro, 2009, p. 497).

${ }^{3}$ Ver Eloy Benito Ruano, Los Infantes de Aragón, Pamplona, CSIC-Escuela de Estudios Medievales, 1952, p. 9. Fundamental trabajo de referencia sobre los Infantes de Aragón, la monografía de Benito Ruano dibuja las sugerentes semblanzas de los Infantes con vistas a arrojar luz sobre el papel que desarrollaron como grupo familiar en la historia de España. Ver también Luis Suárez Fernández, «Los Trastámaras de Castilla y Aragón en el siglo xv (1407-1474)», en Historia de España, dir. Ramón Menéndez Pidal, vol. XV, Madrid 1964, pp. 29-51, pp. 69-122 y 152-186; íd., Nobleza y Monarquía. Puntos de vista sobre la Historia política castellana del siglo XV, Valladolid, Universidad de Valladolid, 1975 (en particular los capítulos VI, VII y VIII).
} 
menor de una importante dinastía (Trastámara en el primer caso, Lara en el segundo), es también sugerido por la curiosa coincidencia en el número, siete en ambos casos, de fuerte carga simbólica (sobre el número siete se volverá más adelante).

\section{2. «¿Qué se hizo aquel trovar?»}

Una vez entronizados los vástagos de la rama menor de los Trastámara en los reinos de Aragón y de Navarra a raíz del compromiso de Caspe y, más tarde, del matrimonio entre Juan y Blanca, heredera al trono navarro (1420), ambas cortes acabaron por ser atraídas a la órbita de la política y de las letras castellanas. Del interés por la poesía de los Infantes de Aragón constituye un elocuente testimonio el gran número de cancioneros compilados en sus ambientes cortesanos. El Cancionero de Palacio (SA7) ${ }^{4}$, que es con toda probabilidad el más antiguo manuscrito que nos ha conservado la producción lírica de las cortes de España, fue copiado en Aragón entre 1441 y 14445; el Cancionero de Herberay (LB2) y el Cancionero de Módena (ME1) destacan, por otra parte, entre las antologías relacionadas con la corte navarra de $\mathrm{Juan}^{6}$, en tanto que los cancioneros de la familia italiana, como el de Stúñiga (MN54), el de Roma (RC1) y el de la Marciana (VM1), que forman parte de la misma sub-rama de origen napolitano, son representativos de la corte literaria del

\footnotetext{
${ }^{4}$ Se hace referencia al sistema de siglas ideadas por Brian Dutton: ver Brian Dutton y Jineen Krogstad, El cancionero del siglo XV, c. 1350-1520 (Biblioteca Española del siglo XV), Salamanca, Universidad de Salamanca, 7 vols., 1990-91.

${ }^{5}$ Ver Cleofé Tato, «El Cancionero de Palacio (SA7), ms. 2653 de la Biblioteca Universitaria de Salamanca (I)» en Cancioneros en Baena: Actas del II Congreso Internacional 'Cancionero de Baena', ed. Jesús L. Serrano, Baena, Ayuntamiento de Baena, 2003, 2 vols., I, pp. 495-523. La más antigua recopilación de poesía cortés en lengua castellana es, obviamente, el Cancionero de Baena, compilado alrededor de 1426-1430; sin embargo, el único ejemplar conservado de aquel cancionero (es decir, el manuscrito que se custodia en la Bibliothèque Nationale de France en París, designado como PN1) es en realidad una copia tardía, posterior al año 1462. El códice designado como SA7 (el llamado Cancionero de Palacio) es, entonces, el más antiguo manuscrito que nos ha conservado la producción lírica de las cortes de España. En palabras de Cleofé Tato, SA7 es «un cancionero que acoge lo que circulaba en el entorno cortesano de Castilla y Aragón en la primera mitad del Xv y que, desde mi punto de vista, aporta el texto de muchas de las composiciones que sonaban en aquellas veladas que asoman en las Coplas de Manrique cuando convoca, en su desfile de muertos ilustres, al rey don Juan y a los Infantes de Aragón: aquí, preferentemente, se da cabida a textos breves, de marcado carácter lírico y de naturaleza amorosa», más representativo, en suma, del gusto poético de la primera mitad del s. Xv respecto de la antología que compuso Juan Alfonso de Baena. Ver Cleofé Tato, «Prolegómenos a la edición del Cancionero de Palacio (SA7)», en El texto medieval: de la edición a la interpretación, ed. Pilar Lorenzo Gradín y Simone Marcenaro, Universidade de Santiago de Compostela, 2012, pp. 299-318 (p. 301).

${ }^{6}$ Ver Vicenç Beltran, «Tipología y génesis de los cancioneros: la reordenación de los contenidos», en Los Cancioneros españoles: materiales y métodos, ed. Manuel Moreno y Dorothy S. Severin, Queen Mary, PMHRS 43, 2005, pp. 9-58 (p. 33 y p. 44).
} 
hijo primogénito de Fernando, Alfonso ${ }^{7}$. Una parte considerable de la producción poética de la corte castellana de Juan II pasó a las cortes de Navarra y de Aragón, integrándose también en los cancioneros que en aquellos entornos fueron copiados. No sorprende, entonces, en las recopilaciones procedentes de los círculos literarios de los Infantes de Aragón, la presencia de clásicos de la corte castellana como Mena y Santillana, fieles políticamente a Juan II, junto con otros poetas vinculados al llamado «partido aragonés» como el castellano Lope de Stúñiga o el aragonés Pedro de Santa $\mathrm{Fe}^{8}$. Por otra parte, es también posible que alrededor de la corte castellana gravitaran autores de origen oriental, catalano o valenciano, tales como el juglar Martín alabado por Alfonso Álvarez de Villasandino en dos composiciones suyas, «Amigos, ya veo acercarse la fin» ( ID 1237: PN1-97, fechado aproximadamente 1398$1405)^{9}$ y «Señor Juan Furtado, yo só quebrantado» (ID 1243: PN1-103) ${ }^{10}$ : de este Martín solo sabemos que solía tañer en occitano, y tal vez podamos suponer que eran la misma persona él y el Martín Ciego autor de una cantiga de escarnio (perdida a causa de una intervención censoria en el único manuscrito que la transmitía, $P N 1$ ) a la que contesta fray Diego de Valencia de León con la cantiga «Cata, Martín Çiego, en toda manera» (ID 1626: PN1-500) ${ }^{11}$.

Entre los siglos XIV y XV en las cortes de Jaime IV de Mallorca, Pedro IV, Juan I y Martín I de Aragón se tradujeron numerosas obras al catalán, y varias de ellas fueron a su vez traducidas del catalán al castellano, una demostración más de la existencia de un recíproco influjo entre los dos grandes reinos peninsulares. Entre las traducciones al catalán que se realizaron en la baja Edad Media $^{12}$ destacan clásicos latinos y medio-latinos tales como las Històries, dits e fets dels Romans de Valerio Máximo en la versión de fra Antoni Canals, que con Enrique de Villena formaría parte de la embajada enviada a Perpignan por Fernando de Antequera en 1415 (de su versión existen al menos

\footnotetext{
${ }^{7}$ Alberto Varvaro, Premesse ad un'edizione critica delle poesie minori di Juan de Mena, Napoli, Liguori, 1964, pp. 59-60.

${ }^{8}$ Sobre la figura histórica de Santa Fe es imprescindible el estudio de Cleofé Tato, Vida y obra de Pedro de Santa Fe, Noia, Toxosoutos, 1999 (en particular las pp. 11-112), además de su valiosa edición crítica, La poesía de Pedro de Santa Fe, Baena, Excmo. Ayuntamiento de Baena, 2004.

${ }^{9}$ «A mí más me plaze oír a Martín / quando canta o tañe algunas vegadas / sus cantigas dulçes, muy bien concordadas / assí en castellano como en limosín» (vv. 33-36). A lo largo del trabajo se citarán todos los textos del Cancionero de Baena (excepto el decir «Siete planetas reales», que aquí se examina) por la edición incluida en Cancionero de Juan Alfonso de Baena, ed. Brian Dutton y Joaquín González Cuenca, Madrid, Visor, 1993.

${ }^{10}$ «Oíd a Martín quando canta e tañe» (v. 35).

${ }^{11}$ Ver Rafael Lapesa, La obra literaria del Marqués de Santillana, Madrid, Ínsula, 1957, pp. 23-24.

${ }^{12}$ Ver Jaume Riera i Sans, «Catàleg d'obres en català traduïdes en castellà durant els segles XIV XV», en Segon Congrés Internacional de la Llengua Catalana, ed. Antoni Ferrando, vol. VIII (Àrea 7. Història de la Llengua), Valencia, Institut de Filologia Valenciana, 1989, pp. 699-710.
} 
tres traducciones castellanas, entre las que destaca la de Juan de Hinestrosa, fechada en 1411), las traducciones anónimas, ambas perdidas, de los tratados de Cicerón De Officiis y De Amicitia, la traducción anónima (falsamente atribuida a Antoni de Vilaragut) de las Tragèdies de Seneca, la traducción aragonesa de la Historia Regum Britannie de Geoffrey of Monmouth (parcialmente incluida en la Grant Crónica de Espanya de Juan Fernández de Heredia) y el De consolació de Boecio en las versiones de fra Pere Saplana y fra Antoni Ginebreda. En la misma dirección viajaron textos romances de gran difusión y éxito como el Milione de Marco Polo (en la versión encargada por Juan Fernández de Heredia, titulada Llibre de les Províncies), o el Breviari d'amor del franciscano Matfré Ermengaud ${ }^{13}$. Finalmente, versiones catalanas de textos fundamentales de la filosofía y medicina antigua, a menudo perdidas o no identificadas con certeza, fueron también traducidas al castellano: es el caso de la Ėtica de Aristóteles, del Lilium Medicine de Gordonio y del Inventari o Collectori de Cirurgia (traducción antigua del Chirurgia de Guy de Chauliac).

En el marco de los contactos políticos y culturales entre Castilla y Aragón, impulsados, sobre todo a partir de la segunda década del siglo, por la acción de Fernando y de sus hijos, se multiplicaron los viajes de poetas castellanos

\footnotetext{
${ }^{13}$ Sobre las traducciones del Breviari d'amor ver, en particular, Matfré Ermengaud, Breviari d'Amor (Biblioteca Nacional de Rusia, Isp. F.v.XIV.N1). Libro de Estudios, ed. Antoni Ferrando Francés y Vicent Martines Peres, Madrid, AyN Ediciones, 2007; Antoni Ferrando Francès, «Noves dades sobre el Breviari d'Amors en llengua catalana», en Miscel-lània Sanchis Guarner, ed. Antoni Ferrando, Barcelona, Publicacions de l'Abadia de Montserrat - Universitat de Valencia, 1992, II, pp. 47-71; Peter T. Ricketts, Connaissance de la littérature occitane. Matfre Ermengaud (1246-1322) et le Breviari d'amor, Perpignan, Presses Universitaries de Perpignan, 2012; Gema Vallín, «El Ms. del Papa Luna: la traducción catalana del Breviari d'amor de Matfre Ermengaud», Centro de Estudios del Maestrazgo, 33 (enero-marzo 1991), pp. 59-66. Sobre la fortuna del Breviari d'amor en tierras ibéricas, ver en particular los trabajos de Jacques Joset, quien ha demostrado que la obra de Matfre Ermengaud es una de las fuentes del Libro de Buen Amor: Jacques Joset, «Juan Ruiz "lector” de Matfre Ermengaud de Béziers», en Juan Ruiz, Arcipreste de Hita, y el «Libro de buen amor». Congreso homenaje a Alan Deyermond, ed. Louise Haywood y Francisco Toro Ceballos, Alcalá la Real, Ayuntamiento de Alcalá la Real - Centro para la Edición de los Clásicos Españoles - Instituto de Estudios Giennenses, 2008, pp. 219-230; íd., «El Breviari d'Amor y el Libro de Buen Amor. Coda», en Juan Ruiz, Arcipreste de Hita, y el «Libro de Buen Amor». Congreso homenaje a Jacques Joset, ed. Francisco Toro Ceballos y Laurette Godinas, Alcalá la Real, Ayuntamiento de Alcalá la Real - Centro para la Edición de los Clásicos Españoles - Instituto de Estudios Giennenses, 2011, pp. 219-221. Para los aspectos iconográficos de los manuscritos del Breviari que circularon en tierras ibéricas, remito a los trabajos de Carlos Miranda García, «La genealogía humana de Cristo en el Breviari d'amor de Matfre Ermengaud de Béziers. Una aproximación a la iconografía del manuscrito S. I. n. ${ }^{\circ} 3$ escurialense», Reales Sitios. Revista del Patrimonio Nacional, 33, 127 (1996), pp. 26-34; íd., «Iconografía de las Edades del Mundo o de la Iglesia en el Breviari d'amor de Matfre Ermengaud de Béziers», Boletín de la Real Academia de la Historia, 191:3 (1994), pp. 455-498; íd., "Actualidad del Breviari d'amor de Matfre Ermengaud de Béziers en el debate astrológico del Trescientos: el caso del manuscrito Res. 203 de la Biblioteca Nacional de Madrid», Boletín de la Real Academia de Buenas Letras de Barcelona, 44 (1993-1994), pp. 101-117.
} 
a la corte aragonesa. Entre ellos estuvo ciertamente el Marqués de Santillana, quien durante su estancia en Aragón conoció la obra de diversos poetas catalanes (Guillén de Bergadán, Pau de Bellviure, Pere March, Jordi de Sant Jordi, Andreu Febrer y Ausiàs March), a los que citaría en su Prohemio y carta al Condestable de Portugal ${ }^{14}$; también residió en Aragón el primo de Fernando, Enrique de Villena, que en su Arte de trovar vertió los preceptos de las Leys d'Amor y de otras artes poéticas provenzales y fue a su vez autor de obras en catalán, como el perdido Los dotze treballs d'Hèrcules, que él mismo tradujo luego al castellano. Además, Enrique de Villena y otros poetas castellanos, como Alfonso Álvarez de Villasandino, estuvieron presentes a la coronación de Fernando, celebrada en Zaragoza el día 11 de febrero de $1414^{15}$.

\section{Fray Diego de Valencia de León y su época}

En el contexto de los acontecimientos políticos que giraron en torno a la figura del futuro Fernando i de Aragón a finales del s. XIV y comienzos del s. Xv, hay que colocar también la obra de fray Diego de Valencia de León, poeta del Cancionero de Baena. Del él no tenemos por lo general gran cantidad de información biográfica documentada. Diversas rúbricas del Cancionero de Baena nos lo presentan como natural de «Valençia de León» ${ }^{16}$, que, basándo-

\footnotetext{
${ }^{14}$ «Los catalanes, valencianos e aun algunos del Reyno de Aragón fueron e son grandes ofiçiales desta arte. Escrivieron primeramente en novas rimadas, que son pies o bordones largos de sýlabas, e algunos consonavan e otros non. Después desto usaron el dezir en coplas de diez sýlabas, a la manera de los lemosís. Uvo entre ellos de señalados onbres, asý en las invençiones commo en el metrificar: Guillén de Bervedá, generoso e noble cavallero, e Pao de Benbibre adquirieron entrestos grand fama. Mosén Pero March, el Viejo, valiente e honorable cavallero, fizo asaz gentiles cosas e, entre las otras, escrivió proverbios de grand moralidad. En estos nuestros tienpos floresçió mosén Jorde de Sant Jorde, cavallero prudente, el qual çiertamente conpuso asaz fermosas cosas, las quales él mesmo asonava ca fue músico exçellente; fizo entre otras una cançión de oppósitos que comiença: "Tos ions aprench e desaprench ensems". Fizo la Passión de amor, en la qual copiló muchas buenas cançiones antiguas, asý destos que ya dixe commo de otros. Mosén Febrer fizo obras nobles, e algunos afirman aya traýdo el Dante de lengua florentina en catalán, no menguando punto en la orden del metrificar e consonar. Mosén Ausias March, el qual aún bive, es grand trobador e omne de asaz elevado spíritu» (Íñigo López de Mendoza, Marqués de Santillana, Prohemio e carta qu'el Marqués de Santillana enbió al Condestable de Portugal con las obras suyas, en Obras completas, ed. Ángel Gómez Moreno y Maxim P.A. M. Kerkhof, Barcelona, Planeta, 1988, pp. 447-448).

${ }^{15}$ A este acontecimiento Villasandino dedicó su decir «Príncipe muy esforçado», número 65 del Cancionero de Baena (ver las notas al texto en Edad Media: lírica y cancioneros, ed. Vicenç Beltran, Barcelona, Ariel, 2002, pp. 212-214). Aun desconociendo este dato histórico, Jole Scudieri Ruggieri había sugerido, a partir de la observación de varias peculiaridades léxicas de sus composiciones, que Villasandino pudo entrar en contacto con la escuela poética de Tolosa durante una hipotética estancia en el reino de Aragón: Jole Scudieri Ruggieri, Cavalleria e cortesia nella vita e nella cultura di Spagna, Modena, Mucchi, 1980, pp. 199-213.

${ }^{16}$ La expresión «fray Diego de Valençia de León» aparece en dos loci: la rúbrica general que abre la sección del cancionero dedicada a la obra de fray Diego, y la rúbrica que introduce su respuesta a la
} 
nos en la relación que fray Diego tuvo con vecinos de Valencia de Don Juan $\mathrm{u}$ otras poblaciones cercanas ${ }^{17}$ podemos identificar con Valencia de Don Juan, población sita en la parte sur de la actual provincia de León, según nos informan las rúbricas de algunas composiciones: un decir (ID 1638: PN1-512) dedicado a Juan Álvarez Osorio, conde de Villalobos, de la comarca de Tierra de Campos, la misma a la que pertenece Valencia de Don Juan; otro decir (ID 1637: PN1-511) dedicado al hebreo Simuel Diosayuda, vecino de Astorga, población que dista unos $50 \mathrm{~km}$ de Valencia de Don Juan; además, el poeta con el que fray Diego intercambia la mayoría de preguntas y respuestas es su amigo Nicolás de Valencia, criado del ya citado Juan Álvarez Osorio y, con toda probabilidad, natural de Valencia de Don Juan a su vez.

La rúbrica que abre la sección del Cancionero dedicada a sus poemas nos informa de que fray Diego era Maestro en Teología y, efectivamente, lo llaman «maestro» varios de los poetas con los que interactúa: Villasandino, Nicolás de Valencia, un doctor anónimo y Ferrant Sánchez Calavera, e incluso él se define a sí mismo «maestro» en una ocasión («que soy muy indigno para maestro ser», n. 486, ID $1611 \mathrm{R} 1610)$. Un documento procedente de los archivos de la orden franciscana, la bula «Viri sacrae doctrinae», fechada en 27 de enero de 1378 y entregada a Pedro Segúdez, superior de la provincia de Santiago, en la que Papa Gregorio XI otorgaba la posibilidad de dar el examen de doctorado para ser nombrado maestro en Teología al fraile «Didacus Valentinus», que era bachiller en teología y llevaba tres años leyendo el Liber sententiarum de Pedro Lombardo en el convento de San Francisco en León ${ }^{18}$, nos haría pensar que fray Diego podía ser ya Maestro en 1378, si es verdad que él y este «Didacus Valentinus» son la misma persona ${ }^{19}$.

célebre pregunta de Sánchez Calavera sobre preciencia y predestinación («Qüistión muy profunda, sotil de verdat», ID 1647 R 1644: PN1-519).

${ }^{17}$ Apoya esta hipótesis Wolf-Dieter Lange, El fraile trobador. Zeit, Leben und Werk des Diego de Valencia de León (1350?-1412?), Frankfurt am Main, Vittorio Klostermann, 1971. La tesis de Valencia de Don Juan ha sido puesta en tela de juicio por el padre Isaac Vázquez Janeiro, quien ha sugerido identificar la ciudad natal de fray Diego con la extremeña Valencia de Alcántara, apoyándose en la interpretación del v. 5 del poema «A vós, reverentes por suma exçelençia» (ID 1502: PN1-377): cfr. Isaac Vázquez Janeiro, «¿Dónde nació fray Diego de Valencia, poeta del Cancionero de Baena?», Antonianum, 64: 2-3 (1989), pp. 366-97. En particular, la frase «yo menos que maestro pero de valençia» (según la lección del manuscrito), contendría para Vázquez Janeiro una sutil alusión a Pedro, maestre de Alcántara, y de hecho la única Valencia que entonces estaba sometida a la orden de Alcántara era la llamada justamente Valencia de Alcántara. Hay que advertir, sin embargo, que la lección «pero», a partir de la cual Vázquez Janeiro construye su argumentación, podría también considerarse una simple corrupción de «Diego» (siendo de hecho posible alguna equivocación entre nombres propios abreviados), y de esta manera en efecto enmiendan Dutton y González Cuenca en su edición del Cancionero de Juan Alfonso de Baena (ed. cit., p. 647).

${ }^{18}$ Se edita el texto de la bula en Vicente Beltrán de Heredia, Bulario de la Universidad de Salamanca (1219-1549), Salamanca, Universidad de Salamanca, 1966, 3 vols., I, p. 427.

${ }^{19}$ Ver Lange, El fraile trobador, ob. cit., p. 35. 
Fray Diego es ciertamente autor de 42 poemas: de ellos, 41 son unica, conservados por el Cancionero de Baena (PN1), mientras que uno (el decir «En son de figura dezir lo que es», ID 0500 R 0532) ha sido transmitido por dos testimonios, PN1 y MH1, este último también conocido como Cancionero de Gallardo o San Román, y conservado en la Real Academia de la Historia de Madrid.

Aunque no tenemos evidencia documental de una hipotética estancia de fray Diego en el reino de Aragón, debemos suponer de todas formas que fue bastante cercano a Fernando y a su corte, porque a sus siete hijos dedicó el decir encomiástico «Siete planetas reales» (ID 1640: PN1-514), un poema de propaganda a favor del héroe de Antequera. El hecho de ser un probable partidario de la causa de Fernando sería compatible con los contactos que fray Diego tuvo, según se desprende de algunas composiciones suyas, con hombres políticamente cercanos a Fernando, tales como el poderoso Condestable Ruy López Dávalos, privado de los reyes Enrique III y Juan II, que en 1416 formaría parte del llamado «partido aragonés» creado por el entonces arzobispo de Toledo Sancho de Rojas para proteger los intereses de los Infantes de Aragón. A petición del Condestable, fray Diego y Villasandino intercambian una serie de preguntas y respuestas (PN1-473 a PN1-476) de argumento filosófico sobre la Fortuna y la predeterminación astral del destino humano, tema que evidentemente no dejaba de tener fuertes implicaciones políticas, y que como es sabido fue objeto de numerosas disquisiciones en la poesía del siglo xv. Además, fray Diego dirige un decir a un «Gonçalo Guayanes», al que llama «fidalgo» y que tal vez podamos identificar con un caballero, del linaje gallego de los Goyanes o López de Goyanes, documentado en el entorno de Don Pedro Enríquez ${ }^{20}$, conde de Trastámara, Sarria y Lemos, como ya ha apuntado en otro trabajo Cleofé Tato ${ }^{21}$ : no parece imposible, aun por razones de proximidad geográfica, que el mismo fray Diego también formara parte del círculo poético del conde Pedro, y quizás del hijo Fadrique, el cual en particular fue muy cercano a Fernando ${ }^{22}$. Las frecuentaciones deducibles

\footnotetext{
${ }^{20}$ Ver Eduardo Pardo de Guevara y Valdés, Los señores de Galicia. Tenentes y condes de Lemos en la Edad Media, A Coruña, Fundación Pedro Barrié de la Maza, 2000, I, p. 243. Tal vez se trate del mismo «Gonçalo López» citado por Ferrán Manuel de Lando en su composición «En el torneo campal» (ID 0536), destinatario, según Dutton y González Cuenca (ed. cit., p. 737), de una pregunta que aparece en el Cancionero de Gallardo o San Román, "Gonçalo Lopez dizen qu'es cordura», atribuida a Pedro de Valcárcel.

${ }^{21}$ Sobre el círculo literario de Fadrique Enríquez, remito a las recientes investigaciones de Cleofé Tato, «Poesía y corte: el duque de Arjona y su entorno», en The Culture of Spanish Verse in the Late Middle Ages (Oxford, 4-6 luglio 2013), en prensa; ead., «Pedro de Valcárcel, poeta de cancionero», en este mismo volumen, pp. 119-142.

${ }^{22}$ Puede ser significativo, a este respecto, el que el segundo verso de la composición dirigida por fray
} 
de sus composiciones, pues, parecen encontrar una correspondencia con la imagen de un fray Diego partidario del regente Fernando que nos ofrece el panegírico que vamos a analizar ${ }^{23}$.

\section{4. «Siete planetas reales»: el panegírico a los siete hijos de Fernando de Antequera}

Objeto del decir que me propongo examinar es la alabanza, en el marco de una visión alegórica, de los siete hijos que Fernando de Antequera tuvo de su mujer Leonor de Alburquerque: Alfonso (1394-1458), María (1396-1445), Juan (1398-1479), Enrique (1400-1445), Leonor (1400?-1445), Sancho (1401-1416) y Pedro (1406-1438). La estructura de la composición contiene dos coplas iniciales con función introductoria, en las que se presenta la visión de las siete plantas que simbolizan a los hijos de Fernando, seguidas por las coplas en alabanza de los hijos varones, con dos coplas para cada uno y, por último, la alabanza de las hijas hembras, María y Leonor, que ocupa un total de dos estrofas. La visión se concluye con una copla final a manera de finida, en la que fray Diego ruega a Dios que bendiga a Fernando y a sus vástagos.

No será superflua una precisión de carácter ecdótico sobre el incipit del poema $^{24}$. Aunque «siete planetas reales» es la lección del único manuscrito que ha conservado el texto (PN1), en la edición de Dutton y González Cuenca del Cancionero de Baena, a diferencia de las precedentes, se enmienda sustituyendo «planetas» por «plantas». En efecto, «plantas» sería el objeto más lógico del predicado «vi salir de dos raízes», en el verso inmediatamente siguiente, y el término es empleado seis veces a lo largo de la composición: en suma, no cabe duda de que el argumento del poema es precisamente la descripción de siete plantas alegóricas que representan a los siete hijos de Fernando. El error (de «planta» a «planeta») se explicaría así por banalización de un hipotético hipercultismo «plancta» (que encuentro documentado en seis ocasiones en $C O R D E^{25}$ ) tal vez contenido en el modelo de PN1. Si, por un lado, parece evidente que la lección del original debió de ser «plantas» y no «planetas», llama la atención, por otro lado, el hecho de que el verso,

Diego a Gonzalo López lea «que Dios vos dé gracia del Rey e del Conde»: esta referencia a un «Conde» podría, en efecto, aludir al mismo conde Don Pedro.

${ }^{23}$ No debe olvidarse, además, que el condado de Mayorga, uno de los dominios más preciados de Fernando de Antequera, se encontraba precisamente en la comarca de Tierra de Campos, cerca de Valencia de Don Juan, lugar de donde supuestamente procedería nuestro fraile.

${ }^{24}$ De ahora en adelante citaré el texto del poema por mi edición crítica, que reproduzco en apéndice.

${ }^{25}$ Real Academia Española, Corpus Diacrónico del Español (CORDE), <http://corpus.rae.es/cordenet. html>. 
con la enmienda «plantas», resulte hipométrico, hipometría que solo podría ser salvada suponiendo diéresis en «siete»; sin embargo, el grupo vocálico ie procedente de $\breve{E}$ latina fue pronunciado siempre, desde los orígenes, como un diptongo, y en poesía era escandido como bisílabo tan solo en muy contadas ocasiones. La ametría hace pensar que el verso está deturpado y que algo más debió de ocurrir, amén del cambio de «plantas» a «planetas», y se trató probablemente de la caída de un monosílabo: hasta podría aventurarse la conjetura de que la lección original contenía el monosílabo «muy» delante de «reales», y que precisamente por la caída de la partícula se produjo la lección «planetas», tal vez por una corrección del copista a fin de restaurar la medida del verso, o bien por atracción del sintagma «siete planetas», empleado con grandísima frecuencia en la literatura medieval y presente en el Cancionero de Baena con tres ocurrencias (CORDE). De todas formas, ante la imposibilidad de probar esta conjetura con razones concluyentes y decisivas, considero más prudente conservar la lección documentada por PN1, que tiene al menos la ventaja de no producir desajustes métricos. Además, no puede excluirse completamente la posibilidad de que la lección original fuera precisamente «planetas»: en efecto, la lección de PN1 podría adecuarse al contexto del poema porque, amén de la acepción principal de «cuerpo celeste», el término (de género femenino en la Edad Media) podía tener también la acepción de «destino» ${ }^{26}$. El Cancionero de Baena ofrece varios ejemplos del empleo del término «planeta» en el sentido de «destino», a menudo en relación con la idea de altura y riqueza, probablemente por el influjo del topos boeciano de la Rueda de la Fortuna: «por que suba en alto la vuestra planeta / e rogad a la Virgen María perfeta / que puge e ensalçe en bien vuestro estado» (PN1103, vv. 22-24), «al digno de alta e rica planeta» (PN1-370, v. 7). A la luz de esta hipótesis, la interpretación de los versos 1-8 podría ser como sigue: de dos raíces (que simbolizan a Fernando y a su mujer) proceden siete destinos reales, es decir, los destinos de los siete vástagos de Fernando, asociados en la compleja alegoría desarrollada en el poema a siete plantas que manan del Paraíso, de dos fuentes perennes; en la superposición entre las «planetas» (v. 1) y las «plantas» (v. 5) podría haber un empleo consciente de la paronomasia

\footnotetext{
${ }^{26}$ Ver Joan Corominas y José Antonio Pascual, Diccionario crítico etimológico castellano e hispánico, Madrid, Gredos, 1980, 6 vols., s. v., donde se observa que el término significa «destino» en el Libro de Buen Amor («enbió por sus sabios, dellos saber querría / el signo e planeta del fijo quel nascía», 129 d), acepción anticuada que falta ya en Covarrubias y Autoridades, pero que sigue viva en catalán. Corominas nos informa de que el vocablo se empleó como femenino no solo en esta acepción, sino también en la principal, y recoge a este propósito los testimonios del Libro del Acedrex (372.8) y del Universal Vocabulario en latín y en romance de Alonso de Palencia ("anno que dizen grande quando todas las planetas juntamente vienen en vno al primer curso", $21 \mathrm{~d}$ ).
} 
por parte de fray Diego, quien utiliza a menudo este recurso en su producción poética, incluso en final de verso. Se trata ciertamente de una hipótesis atrevida, pero que merecería la pena considerar.

\section{1. «Et egredietur virga de radice Jesse, et flos de radice ejus ascendet» (Is. 11, 1)}

La alegoría que se desarrolla en el poema, en particular en las coplas i y II, es en realidad muy compleja y sería demasiado banal reducirla a la simple visión de siete plantas que simbolizan a los siete hijos de Fernando de Antequera. La fuente de esta imagen es con toda probabilidad la profecía de Isaías (11, 1-2): «Et egredietur virga de radice Jesse, et flos de radice ejus ascendet. Et requiescet super eum spiritus Domini: spiritus sapientiae et intellectus, spiritus consilii et fortitudinis, spiritus scientiae et pietatis; et replebit eum spiritus timoris Domini». En Apocalipsis 22, 16 se retoma esta misma profecía, y allí es el mismo Cristo el que afirma: «Ego sum radix, et genus David, stella splendida et matutina $\rangle^{27}$. A partir de los comentarios de Tertuliano (De carne Christi, XXI, 5; Corpus Christianorum Lat., II, 2, p. 912), se impuso una interpretación según la cual la «virga» salida de la raíz de Jesé era la Virgen, y su flor Cristo, idea que se encontrará luego en San Ambrosio, San Jerónimo, Rabano Mauro y otros, y que será desarrollada sobre todo en los comentarios cistercienses al Cantar de los cantares, por ejemplo en los Commentaria de Ruperto de Deut ${ }^{28}$. La combinación de la imagen contenida en Isaías 11, 1 con la enumeración de la genealogía de Cristo (Lc. 3, 23-28; Mt. 1, 1-17) originaría, a partir del s. XI, el motivo iconográfico del árbol de Jesé$^{29}$. El que fray Diego tuviera presente la profecía de Isaías en este pasaje me parece confirmado por la referencia a la «verga» en el verso 16 («por virtud d'amas e dos / una verga se regía»). Otro elemento de la profecía de Isaías que fray Diego retoma en su visión alegórica es el motivo de las siete plantas: en el pasaje de Isaías, en efecto, se encuentra el origen de la doctrina de los siete dones del Espíritu Santo, es decir, sabiduría, entendimiento, consejo, fortaleza, ciencia, piedad y temor de Dios («requiescet super eum

${ }^{27}$ Cito por la Vulgata: Biblia sacra. Iuxta vulgatam versionem, adiuvantibus Bonifatio Fischer OSB (et al.), recensuit et brevi apparatu instruxit Robertus Weber OSB, Stuttgart, Württembergische Bibelanstal, 1969, 2 vols.

${ }^{28}$ Sobre todo respecto a los siguientes versos del Cantar: «dum esset Rex in accubitu suo, nardus mea dedit odorem suum. Fasciculus myrrhae dilectus meus mihi; inter ubera mea commorabitur. Botrus cypri dilectus meus mihi in vineis Engaddi. Ecce tu pulchra es, amica mea! ecce tu pulchra es! Oculi tui columbarum» $(1,11-14)$.

${ }^{29}$ Ver, sobre todo, Arthur Watson, The Early Iconography of the Tree of Jesse, London-Oxford, Oxford University Press, 1934. 
spiritus Domini: spiritus sapientiae et intellectus, spiritus consilii et fortitudinis, spiritus scientiae et pietatis; et replebit eum spiritus timoris Domini»), generalmente representados, en la tradición iconográfica del árbol de Jesé, como siete palomas posadas en otras tantas ramas del árbol. En su poema, entonces, fray Diego aprovecha varios elementos de esta profecía para construir sobre ellos una alegoría bastante compleja, con la que pretende glorificar la dinastía de Fernando de Antequera: en su visión, la raíz de Jesé se convierte en dos raíces, "poderosas e feliçes», que simbolizan a Fernando y a su mujer Leonor, a los que asocia, además, las propiedades de las fuentes del Paraíso, y las siete ramificaciones de la verga de Jesé se convierten en «plantas», representaciones de los siete hijos del matrimonio, implícitamente asociados a los siete dones del Espíritu Santo. Otra posible inspiración para la imagen podría ser, además, la tradición iconográfica franciscana que se remonta al Lignum vite de san Buenaventura y al Arbor vite crucifixe Jesu de Ubertino da Casale, en los que se representaba a la humanidad como un árbol que tiene sus raíces en Dios.

La visión posee, huelga decirlo, una connotación ideológica muy clara ${ }^{30}$. Una dinastía, la rama menor de los Trastámara, se levanta como un árbol robusto a la sombra del trono de Castilla, y de sus poderosas raíces brotan otras siete ramas: es esta la idea central de la composición, y no podría quedar mejor representado el diseño político del hijo segundón de Juan I Trastámara. Así lo resume muy bien Jaime Vicens Vives ${ }^{31}$ :

La protección de Juan I hacia el príncipe Fernando había convertido a éste en un poderoso magnate en tierras castellanas. En las Cortes celebradas en Guadalajara poco antes de su muerte, en 1390, le invistió, en presencia de su hermano Enrique, príncipe heredero, con el señorío de Lara, el ducado de

\footnotetext{
${ }^{30}$ Representaciones iconográficas del árbol de Jesé se encuentran en los manuscritos de las Cantigas de Santa María: me parece significativo, a este respecto, el que en la miniatura que acompaña la cantiga 20 en el códice $T$ aparezca junto al árbol Alfonso $X$ arrodillado, en posición orante, con los escudos de Castilla y León. Esta imagen, que ha sido interpretada como un elemento de exaltación monárquica, con función esencialmente ideológica y de propaganda, podría representar tal vez un antecedente de la alegoría de fray Diego. Ver Ana Domínguez Rodríguez, «En torno al Árbol de Jesé (siglos XI-XIII). Tres ejemplos en las Cantigas de Santa Maria», en Cobras e Son. Papers on the Text, Music, and Manuscripts of the "Cantigas de Santa Maria», ed. Stephen Parkinson, Oxford, Legenda - Oxford University Press, 2000, pp. 70-92; íd., «La Virgen, rama y raíz. De nuevo con el árbol de Jesé en las Cantigas de Santa Maria», en El Scriptorium alfonsí: de los Libros de Astrología a las "Cantigas de Santa María» (Cursos de Verano de El Escorial), ed. Jesús Montoya Martínez y Ana Domínguez Rodríguez, Madrid, Editorial Complutense, 1999, pp. 173-214. Para el aspecto iconográfico de la profecía literaria de objetivo político, remito al estudio de Paola Guerrini, Propaganda politica e profezie figurate nel tardo Medioevo, Napoli, Liguori Editore, 1997.

${ }^{31}$ Jaime Vicens Vives, Juan II de Aragón (1398-1479). Monarquía y revolución en la España del siglo XV, Barcelona, Teide, 1953, p. 4.
} 
Peñafiel y el condado de Mayorga; le hizo cesión de las villas de Cuéllar, San Esteban de Gormaz y Castrogeriz y le asignó medio millón de maravedises anuales a expensas del tesoro real. Además le puso sobre la cabeza una «guirnalda de aljófar», símbolo de su preeminencia ducal, y le dió armas condignas a su alta estirpe: un castillo y un león, a la derecha, y las barras catalanas, a la izquierda, estas últimas en calidad de hijo de doña Leonor de Aragón. Para un niño de diez años, este pingüe «heredamiento» significaba la elevación al primer plano de la escena política después del monarca; el cual, por otra parte, en su testamento firmado en Cellorico, le había destinado como futuro propietario de Medina del Campo y Olmedo, entonces disfrutadas por doña Constanza, hija de Pedro i el Cruel y esposa del príncipe inglés Juan de Gante.

Por si todo esto no fuera suficiente, Fernando se benefició, además, del matrimonio con su tía Leonor, la «rica hembra», para ampliar de manera considerable su patrimonio y reforzar sus derechos dinásticos al trono castellano. Doña Leonor era hija del Infante Sancho de Castilla, conde de Alburquerque (hijo a su vez de Alfonso XI de Castilla y hermano de Enrique II); su madre era Beatriz de Portugal, hija bastarda del rey de Portugal Pedro I el Justiciero y de Inés de Castro, dama de compañía de la segunda mujer de éste. Su boda con Leonor trajo a Fernando la posesión de importantes núcleos en Castilla, La Rioja y Extremadura ${ }^{32}$ : si a ello añadimos la donación que Juan I le había otorgado en 1390, nos encontramos ante un dominio sin parangón en la época. Pero incluso este patrimonio enorme no era suficiente por sí solo para dotar a siete hijos de la manera que el ambicioso Fernando hubiera deseado. Así, de acuerdo con el testamento de su hermano Enrique III (donde se hablaba de este propósito como convenido anteriormente), en 1408 prometió su hija mayor, María, al futuro Juan II de Castilla, y el primogénito Alfonso (el futuro Alfonso el Magnánimo) a María de Castilla, hermana del ya citado Juan II. El matrimonio de la otra hija, Leonor, con Dom Duarte, heredero al trono portugués, será pactado solo en 1428, ya fallecido Fernando, por Alfonso «el Magnánimo» y el Duque de Coimbra, Dom Pedro, hermano de Dom Duarte. En los versos 105-106 de su poema, fray Diego profetiza con acierto el destino de María y Leonor, «casadas muy altamente / con grandes fijos de reyes»: probablemente se expresa en este pasaje un deseo genérico, que refleja las intenciones de Fernando de casar sus hijas con hijos de reyes o herederos, pero se puede suponer que fray Diego tuviera conocimiento del compromiso entre María y el futuro rey de Castilla, porque de varios datos textuales se infiere,

${ }^{32}$ Leonor poseía, por herencia, las tierras de Haro, Briones, Cerezo y Belorado en La Rioja, Ledesma y las llamadas Cinco Villas (Almendra, Monleras, Villaseco de los Reyes, Sardón de los Frailes y El Manzano) en León, Alburquerque, Medellín, La Cadesera, Alconetar, Alzagala y Alconchel en Extremadura. 
como veremos más adelante, que debió de componer este poema después de 1408, es decir, cuando ya se había hecho esta promesa matrimonial.

En cambio, Juan, el segundo hijo, había sido prometido en 1403, a los pocos años de edad, a Isabel de Navarra, hija de Carlos III. En 1415 Fernando rompió el compromiso para prometer Juan a la reina Juana de Nápoles, con vistas a hacer de él una especie de emperador mediterráneo: Juan debería ocuparse de las posesiones mediterráneas de la corona de Aragón, y por ello fue lugarteniente del rey de Aragón en el reino de Sicilia y Cerdeña entre 1415 y 1416. Sin embargo, tampoco el compromiso con Juana de Nápoles se cumplió, debido esta vez al rápido viraje de la reina, que prefirió casarse con el conde de La Marche. Al final Juan casó en 1420 con la hermana mayor de Isabel, Blanca de Navarra, viuda del hijo de Martín I de Aragón, el rey de Sicilia Martín I «el Joven», y heredera al trono navarro.

Fue también por vía matrimonial que el tercer hijo, Enrique, consiguió apropiarse del codiciado Marquesado de Villena, ya prometido a su hermano mayor, Alfonso, por su casamiento con María de Castilla, y luego sustituido por la suma de 200000 doblas. Enrique casó con la otra hermana de Juan II de Castilla, Catalina, que de hecho había sido prometida a uno de los Infantes de Aragón, sin que en ninguna fuente se especifique a cuál, desde que Juan II de Castilla casó con María. Las crónicas sugieren que Juan había estado realmente enamorado de Catalina en su juventud, pero a partir de 1420, casado ya aquél con Blanca de Navarra, Enrique aprovechó la oportunidad para pedir la mano de Catalina, lo cual causaría muchas tensiones entre los dos hermanos, según los cronistas ${ }^{33}$.

Baste, de momento, este rápido excursus. Por lo que atañe a la política dinástica de Fernando, me encuentro esencialmente de acuerdo con lo que afirma Jaime Vicens Vives:

por amor paterno o por ambición política, don Fernando procuró engrandecer su casa, sin importarle gran cosa que pudiera echar sombra sobre la dinastía reinante. Podía limitarse a garantizar para su prole la copiosa herencia paterna y materna; no lo quiso, porque la deseaba ceder íntegra o en su mayor porción a uno de sus hijos. Podía limitarse a consolidar las mercedes y asignaciones hechas a cada uno de ellos por Enrique III; pensó que era poco, sobre todo antes de 1410, cuando aún no había brillado en su firmamento la favorabilísima coyuntura de la muerte sin sucesión de su tío Martín el Humano de Aragón. En las circuntancias de los años inmediatos a su promoción a la regencia

${ }^{33}$ Para un estudio del perfil biográfico de Don Enrique y de su imagen literaria, que impregna gran parte de la producción poética de la época, remito a Eloy Benito Ruano, «Fortuna literaria del Infante D. Enrique de Aragón», Archivum, 14 (1964), pp. 161-201. 
castellana, Fernando de Antequera intentó robustecer su poder contra cualquier posible cambio de la fortuna, de modo que hoy sería vano pretender descifrar qué motivo imperó primordialmente en su corazón en el empeño de aumentar la dote de sus hijos: si el político o el familiar. Es posible que ambos se aliaran inextricablemente en el fomento de una ambición casi morbosa ${ }^{34}$.

\section{2. «Videbas ita, donec abscissus est lapis de monte sine manibus» (Dan. 2, 34)}

El eje principal en torno al que gira la visión alegórica de los siete hijos / plantas en el decir de fray Diego, es el tema de la lucha contra el Infiel. De hecho, a su compromiso en la guerra contra el Islam se debe la imagen que las crónicas nos han dejado de Fernando, la de un espejo de caballeros, valeroso continuador de la cruzada contra los musulmanes. Una cláusula del testamento de Enrique III preveía el reparto de las provincias del reino entre los corregentes, Catalina de Lancaster y Fernando, cuando ellos no estuvieran juntos, y este reparto era tarea que correspondía al Consejo Real: en el reparto, Fernando obtuvo la mitad meridional del reino, gracias sobre todo a los votos favorables de sus hijos Alfonso y Juan, que apresuradamente habían tomado los asientos que en el Consejo les correspondían, pese a su joven edad (trece y nueve años respectivamente) $)^{35}$. Después de la primera, costosa e infructuosa campaña de 1407, Fernando consiguió que sus hijos Enrique y Sancho, ambos menores, fueran nombrados maestres de las dos grandes Órdenes Militares de Santiago y Alcántara, hecho sobre el que volveré más adelante: dado que Enrique y Sancho eran solo maestres de nombre, quien ahora controlaba la caballería y las cuantiosas rentas procedentes de las dos Órdenes Militares era en efecto su padre, y fue así como se llegó a la legendaria rendición de Antequera, al término de un largo asedio, el 16 de septiembre de 1410.

En su decir, fray Diego desarrolla el tema de la cruzada contra el musulmán en particular en los versos 53-64, dedicados a Enrique, Maestre de Santiago, y en los versos 65-68, dedicados a Sancho, Maestre de Alcántara. El tema de la Cruzada contra los infieles se asocia a la idea de seguir la reconquista por el Norte de África hasta tomar Jerusalén, a la que se alude en particular en los versos 63-64, con las referencias al Ultramar y a Cartago. La base de esta idea se encuentra en la tradición que profetizaba que un rey de Occidente, el último emperador, expulsaría los musulmanes de la península Ibérica, conquistaría

\footnotetext{
${ }^{34}$ Vicens Vives, Juan II de Aragón, ob. cit., p. 8. Sobre la figura histórica de Juan II de Aragón, ver también íd., «Los Trastámaras y Cataluña», en Historia de España, dir. Ramón Menéndez Pidal, ob. cit., vol. XV, 1964, pp. 745-785.

${ }^{35}$ Ver Juan Torres Fontes, Dos divisiones politico-administrativas en la minoría de Juan II de Castilla, Murcia, Anales de la Universidad de Murcia, 1947.
} 
el Norte de África y recuperaría Jerusalén, y se volverían entonces a unir la Iglesia de Roma y la de Constantinopla ${ }^{36}$. Basada en profecías antiguas, procedentes de los imperios romano y bizantino, esta tradición fue ampliada y refundida en la alta Edad Media y adaptada a la dinastía aragonesa por Arnau de Vilanova en el Tractatus de cymbalorum ecclesie (1301): al médico catalán, que había entrado en contacto con los escritos proféticos de Gioacchino da Fiore ${ }^{37}$, se debe la formulación más célebre de esta profecía, el Vae mundo in centum annis ${ }^{38}$. Finalmente, la idea fue acogida por la propaganda ideológica de Fernando de Antequera y, más tarde, será también aprovechada por su hijo Alfonso el Magnánimo y, sobre todo, por Fernando el Católico ${ }^{39}$. Otro personaje cuyas profecías habían servido para la legitimación de la dinastía Trastámara es el Infante fray Pedro de Aragón, tío de Pedro «el Ceremonioso» y figura de gran influencia en la corte aragonesa. Franciscano a su vez, el Infante Pedro (o Pere d'Empúries) había profetizado sobre la lucha fratricida entre Pedro I de Castilla y Enrique Trastámara (retomando los vaticinios de Merlín, Gioacchino da Fiore, Jean de Roquetaillade, Arnau de Vilanova y otros $)^{40}$ y había descrito a Enrique como el vespertilio destinado a reconquistar Jerusalén y subyugar el mundo ${ }^{41}$.

${ }^{36}$ Ver Vicenç Beltran, «Edat mitjana, ideologia i literatura», en Literatures ibèriques medievals comparades, ed. Rafael Alemany Ferrer y Francisco Chico Rico, Alicante, Universidad de Alicante, 2012, pp. 103-132 (en particular la p. 113). Expreso mi agradecimiento al Prof. Beltran, cuyas valiosas sugerencias y observaciones me ayudaron mucho en la elaboración de este trabajo.

${ }^{37}$ Sobre Gioacchino da Fiore es imprescindible el trabajo de Marjorie Reeves, The Influence of Prophecy in the Later Middle Ages. A Study in Joachimism [1969], Notre Dame - London, University of Notre Dame Press, 1993.

${ }^{38}$ Edita esta profecía Josep M. ${ }^{a}$ Pou i Martí, Visionarios, beguinos y fraticelos catalanes (siglos XIII-XV), Vich, Editorial Seráfica, 1930, pp. 54-55 (reimpreso con estudio preliminar de Juana Mary Arcelus Ulibarrena, Madrid, Colegio Cardenal Cisneros, 1991, y con estudio preliminar de Albert Hauf i Valls, Alicante, Instituto de Cultura Juan Gil Albert, 1996). Ver, también, Isabelle M. Rousseau, «La prophétie comme outil de légitimation: trois lectures du Vae mundo (XIV siècle)», en Lucha política. Condena y legitimación en la España medieval, ed. Julio Escalona y Georges Martin, Paris, ENS Éditions, 2004, pp. 63-99.

${ }^{39}$ Ver Eulàlia Duran y Joan Requesens, Profecia i poder al Renaixement: Texts profètics catalans favorables a Ferran el Catòlic, Valencia, Edicions Tres i Quatre, 1997; Alain Milhou, Colón y su mentalidad mesiánica en el ambiente franciscanista español, Valladolid, Casa Museo Colón - Seminario Americanista de la Universidad de Valladolid, 1983.

${ }^{40}$ Ver Maria Mercè López Casas, «Las profecías de Merlín y la legitimación de los Trastámara», en Magia, Brujería y Esoterismo en la Historia, ed. Antonia Víñez Sánchez y Santiago Moreno Tello, Cádiz, Asociación Cultural y Universitaria Ubi Sunt?, 2006, pp. 45-62 (esp. pp. 54-55); Pou i Martí, Visionarios, ob. cit., pp. 308-396; Lluís Cabré, «L'infant Pere d’Empúries i la tradició familiar: estampes en el setè centenari del seu naixement», Mot So Razo, 4 (2005), pp. 69-83. Sobre la propaganda ideológica promovida por la dinastía Trastámara para su legitimación, ver también Emilio Mitre Fernández, «La historiografía bajomedieval ante la revolución trastámara: propaganda política y moralismo», en Estudios de Historia Medieval en homenaje a Luis Suárez Fernández, ed. Miguel Ángel Ladero Quesada y Julio Valdeón Baruque, Valladolid, Universidad de Valladolid, 1991, pp. 333-348.

${ }^{41}$ Ver Alain Milhou, «La chauve-souris, le Nouveau David et le Roi Caché (trois images de 
El tema de la lucha contra los infieles vuelve a aparecer, hacia el final del poema, en las dos coplas dedicadas al último hijo de Fernando, Pedro, nacido posiblemente en 1406. Aprovechando las posibilidades asociativas que ofrece su nombre, fray Diego construye la alabanza de Pedro alrededor de la imagen de una piedra cortada del monte no con mano de hombre. Por la referencia al profeta Daniel en el verso 87, queda claro que la imagen de la piedra debe mucho al episodio bíblico sobre el sueño profético de Nabucodonosor (Daniel 2, 31-45): el rey babilónico había soñado una estatua hecha de diferentes metales, con la cabeza de oro, el pecho y los brazos de plata, el vientre y los muslos de bronce, las piernas de hierro, los pies en parte de hierro y en parte de arcilla; una piedra cortada, no con mano, había herido los pies de la estatua y junto con ellos había derribado el resto de la estatua, de la que no quedó rastro alguno; y la piedra se erigió como un monte, abarcando toda la tierra. Entre los magos y videntes consultados por Nabucodonosor tan solo Daniel consiguió descifrar el enigma, interpretando los cuatro metales como los símbolos de cuatro diferentes imperios, el babilónico de $\mathrm{Na}$ bucodonosor (simbolizado por la cabeza de oro), y tres imperios venideros, inferiores a éste. El sentido de la visión es que, en la época de estos últimos imperios, Dios levantará un reino (representado por la piedra) que no será jamás destruido, aplastará todos los demás imperios y durará para siempre. Así, la paronomasia «piedra» / «Pedro» se convierte en el punto de partida de la comparación entre Pedro y la piedra cortada ${ }^{42}$ por la gracia divina, destinada a someter («por que ponga so su planta») y aplastar («las sus azes

l'empereur des derniers temps dans le monde ibérique: XIII $-\mathrm{XVII}{ }^{\mathrm{e}} \mathrm{ss}$.)», Mélanges de la Casa de Velázquez, 18 (1982), pp. 61-78 (en particular la p. 66).

${ }^{42}$ La expresión empleada por fray Diego en los vv. 89-90 («piedra del monte tajada / non por mano humanal») traduce obviamente el pasaje «abscissus est lapis de monte sine manibus» (Dan. 2, 34). La elección de vocablos («piedra... tajada») recuerda curiosamente (y tal vez no por casualidad) el nombre de otro personaje cuyas profecías circularon ampliamente en el reino de Aragón en la baja Edad Media: el franciscano de Alvernia Jean de Roquetaillade (Johannes de Rupescissa), llamado en catalán Joan de Rocatallada o Peratallada. Hay controversia sobre su lugar de nacimiento: según la mayoría de los estudiosos era francés, pero algunos, tales como Don Marcelino Menéndez y Pelayo, identifican su solar nativo con el pueblo de Peratallada, sito en el Bajo Ampurdán y provincia de Gerona (ver Historia de los heterodoxos españoles [1856-1912], Santander, CSIC, 1948, 8 vols., II, p. 308). Influido a su vez por Gioacchino da Fiore y, sobre todo, Pierre de Jean Olieu, Jean de Roquetaillade había retomado las profecías de Arnau de Vilanova, sobre todo en el Breviloquium de oneribus orbis (1354-1355), entendiendo que de la estirpe de Pedro III de Aragón había de proceder un flagellum Dei, que subyugaría Europa y África. Sobre la figura de Jean de Roquetaillade, ver Jeanne Bignami-Odier, Études sur Jean de Roquetaillade (Johannes de Rupescissa), Paris, Vrin, 1952; Les textes prophétiques et la prophétie en Occident (XII'-XVI Actes de la table ronde (Chantilly, 30-31 mai 1998), ed. André Vauchez, Roma, École française de Rome, 1990; André Vauchez, «Jean de Roquetaillade (+1366 ca). Bilan des recherches et état de la question», en Eschatologie und Hussitismus: internationales Kolloquium, Prag, 1-4 September 1993, ed. Alexander Patschovsky y Frantisek Smahel, Praha, Historisches Institut, 1996, pp. 25-37. 
les quebrante») los ejércitos musulmanes y a unificar la Iglesia de Roma, entonces afectada por el Cisma de Occidente (1378-1417) ${ }^{43}$. En este sentido, es significativo el carácter diamantino que fray Diego atribuye a la piedra: el diamante, que es el mineral más duro conocido, capaz, gracias a su dureza, de rayar cualquier material existente, simboliza en la tradición católica la iluminación y la inalterabilidad de la fe.

Evidentemente el último reino, enviado a destruir todos los reinos temporales y a durar para siempre, es el reino mesiánico de Dios, que surgirá en los tiempos finales. La referencia a esta profecía de Daniel no me parece en absoluto casual: el texto de fray Diego se coloca plenamente dentro de la estela de la literatura de propaganda, que normalmente hacía uso del imaginario mesiánico y escatológico ${ }^{44}$ para vehicular la ideología a la que servía. En este sentido, el uso político de textos apocalípticos (tales como el Libro de Daniel, uno de los más célebres) permitía a reyes, dinastías y poderes espirituales legitimar su poder y sus intereses, funcionando como instrumento de cohesión dentro de los grupos correspondientes y contra los enemigos:

les rois, dans leur propagande, pouvaint manipuler les prophéthies -tout en leur accordant parfois, paradoxalement, une certaine créance- afin de conférer à leur action un prestige surnaturel, soit face aux factions qui, dans le royaume, pouvaint leur être hostiles, soit face au pape dont ils cherchaient à limiter les exigences politiques et financières, soit face aux autres souverains de la Chrétienté, pour légitimer leur impérialisme territorial ${ }^{45}$.

\footnotetext{
${ }^{43}$ En la Commedia (Inferno XIV, 102-120) Dante retoma la imagen bíblica de la estatua hecha de diferentes metales, combinándola con la fuente clásica de las Metamorfosis de Ovidio (I, 89-131), para representar al Veglio di Creta, símbolo de la historia de la humanidad y del pecado.

${ }^{44}$ Sobre la difusión en tierras ibéricas de las corrientes profético-escatológicas, relacionada sobre todo con los ambientes franciscanos del reino de Aragón, remito a Pere Bohigas, «Profecies catalanes dels segles XIV i XV. Assaig bibliogràfic», Butlletí de la Biblioteca de Catalunya, 6 (1920-22), pp. $24-$ 49; íd., «Profecies de Merlí», Butlletí de la Biblioteca de Catalunya, 8 (1928-32), pp. 253-279; íd., «La “visión de Alfonso X” y las "Profecías de Merlín”», Revista de Filología Española, 25 (1941), pp. 383-398; Pou i Martí, Visionarios, ob. cit.; Milhou, «La chauve-souris», art. cit.; Isabelle M. Rousseau, L'eschatologie royale de tradition joachimite en Aragon (XIII-XV siècle). Édition et étude d'un corpus prophétique, Lyon, École normale supérieure lettres et sciences humaines, 2003. Ver también José Guadalajara Medina, Las profecías del Anticristo en la Edad Media, Madrid, Gredos, 1996. Acerca de la presencia franciscana en el aparato monárquico de los Trastámara puede consultarse José Manuel Nieto Soria, «Franciscanos y franciscanismo en la política y en la corte de la Castilla Trastámara (13691475)», Anuario de Estudios Medievales, 20 (1990), pp. 109-131. Además, el mismo autor ofrece un análisis de la representación ideológica de la realeza en la poesía de los cancioneros castellanos en «Apología y propaganda de la realeza en los cancioneros castellanos del siglo XV. Diseño literario de un modelo político», En la España Medieval, 11 (1988), pp. 185-221.

${ }^{45}$ Milhou, «La chauve-souris», art. cit., p. 63.
} 


\section{Hipótesis de datación del texto y conclusiones}

Llegamos, finalmente, al problema de la datación de este poema. Dado que en él fray Diego se dirige tanto a Enrique como a Sancho empleando el título de «Maestre» (en los versos 51 y 68, respectivamente), hay que concluir que ambos habían recibido el título antes de que el poema fuera escrito. Sabemos que Sancho fue investido Maestre de la Orden de Alcántara el 23 de enero de 1409 en la Iglesia de San Pablo en Valladolid: a través del entonces obispo de Palencia Sancho de Rojas, Fernando consiguió que el capítulo de la Orden eligiera a su hijo como sucesor del Maestre Fernán García de Villalobos, que había muerto. En el transcurso del mismo año hubo otra vacante, por el fallecimiento del Maestre de Santiago Lorenzo Suárez de Figueroa: para superar la oposición de una parte del capítulo, que defendía en cambio la candidatura del comendador mayor de Castilla, Garci Fernández de Villagarcía, Fernando obtuvo para su hijo Enrique el nombramiento directo, sin elección y con dispensa de edad, por Papa Benedicto XIII, al que ya había garantizado su precioso apoyo en ocasión del nombramiento de su sobrino, también llamado Pedro de Luna ${ }^{46}$, como Arzobispo de Toledo. De este modo, el Infante fue elegido por unanimidad en Uclés e investido Maestre en Becerril en fecha indeterminada, en $1409^{47}$.

Así, el término post quem para la datación del poema sería el invierno $1409-1410^{48}$. El término ante quem más lógico sería, por supuesto, el año 1416, en el que fallecieron tanto Fernando como su hijo Sancho. El decir constituye la documentación más tardía de la actividad poética de fray Diego, ya que se trata de la última de las composiciones fechables. Sin embargo, se podría adelantar de unos pocos años el término ante quem: como fray Diego

\footnotetext{
${ }^{46}$ Pedro de Luna fue hijo de Juan Martínez de Luna y Teresa de Albornoz y primo de Benedicto XIII. En calidad de nuncio pontificio, desempeñó un papel de primera importancia para que la asamblea clerical del reino, celebrada en el mes de noviembre de 1380, declarase que Castilla y León aceptaba como Papa a Clemente VII. En 1383 participó en las negociaciones del matrimonio entre Juan I y Beatriz de Portugal. Figura también en los cancioneros PN1 y PN2 como autor de una composición, «Bestias son de las montañas» (PN1-154) y destinatario de varios poemas de Villasandino (PN1-153 a 158) y un decir anónimo, «Señor, bien fundado» (PN2-15). La única composición que se le atribuye es una respuesta a la petición que le dirige Villasandino, «Primado de las Españas» (PN1-153). Según Dutton y Cuenca (ed. cit., p. 179, nota), que retoman una hipótesis ya formulada por los responsables de la edición de 1851 del Cancionero de Baena, el autor de la respuesta no sería Pedro de Luna sino un poeta anónimo que se habría comprometido a responder en nombre del clérigo. Perea Rodríguez, en su monografía sobre los poetas del Cancionero de Baena, parece en cambio inclinarse a considerar al mismo Pedro de Luna como el efectivo autor de la composición (ver Óscar Perea Rodríguez, La época del Cancionero de Baena: los Trastámara y sus poetas, Baena-Córdoba, Ayuntamiento de Baena-Diputación de Córdoba, 2009, p. 59).

${ }^{47}$ Ver Vicens Vives, Juan II de Aragón, ob. cit., p. 10.

${ }^{48}$ Ver Suárez Fernández, «Los Trastámaras de Castilla y Aragón», art. cit., pp. 38-39.
} 
llama a Fernando «Infante» (versos 85 y 117), se podría concluir que el poema debió de ser redactado antes del compromiso de Caspe (1412), con el que el Infante Fernando fue proclamado rey de Aragón. Evidentemente, si éste fuera ya rey fray Diego nunca dejaría de llamar a sus hijos «Infantes», título que, con la única excepción de Juan, rey de Navarra, todos sus hijos ostentarían siempre. Además, resulta un tanto sorprendente, en un poema de tipo encomiástico, la falta de alusiones a la toma de Antequera, del septiembre de 1410: esta consideración podría llevarnos a adoptar entonces esta fecha como terminus ante quem $\mathrm{y}$, por lo tanto, a datar este decir entre enero y septiembre de $1410^{49}$. Aun así, este poema resulta el más tardío dentro del corpus poético de fray Diego.

Quisiera llamar la atención, sin embargo, sobre los versos 37-38 en los que, hablando de Juan, se hace referencia al señorío de Lara y Castrogeriz («Castro traiá por vandera / e Señor de los de Lara»), único pasaje en todo el poema en el que se alude a los señoríos de los Trastámaras menores. Si fray Diego compuso el poema antes del compromiso de Caspe, es difícil explicar por qué atribuye el señorío de Lara y Castrogeriz al segundón Juan y no al primogénito Alfonso, que en cambio tenía derecho a heredarlos ambos. Según el diseño de Fernando, Alfonso debería ser la cabeza de la dinastía en Castilla mientras Juan, Enrique y Sancho, que recibirían una dote menor, serían compensados respectivamente por el trono de Navarra, el maestrazgo de Santiago y el de Alcántara.

Después de Caspe, sin embargo, Fernando tuvo que reconsiderar la repartición del patrimonio entre sus hijos: ahora el primogénito Alfonso estaba destinado a heredar con el tiempo la corona aragonesa, por lo que se le apartó de los señoríos castellanos, que pasaron a Juan: éste sería entonces Duque de Peñafiel, Conde de Mayorga y señor de Lara, Castrogeriz, Medina del Campo, Olmedo, Cuéllar, Villalón, Haro, Belorado, Briones y Cerezo; a Enrique, que sería Conde de Alburquerque, fueron asignados los señoríos de Medellín, Ledesma, Alba de Liste, Urueña, Tiedra, Alconchel, Azagala y San Felices de Gallegos, dote menor que la de Juan, más que compensada, de todas formas, por las rentas del maestrazgo de Santiago. En el escenario que se abría con su proclamación real, Fernando proyectaba hacer de Juan y Enrique las cabezas de la dinastía en Castilla: el segundón Juan, heredero de la mayor parte del patrimonio en vez del primogénito Alfonso, y también del trono de Navarra, debería ser el protector militar del partido, mientras que Enrique, cuyo patrimonio era menor $\mathrm{y}$, por lo tanto, más tranquilizante, podría disponer a su

${ }^{49}$ Ver Lange, El fraile trobador, ob. cit., p. 45. 
antojo de la potencia económica y militar de la Orden de Santiago, ejerciendo su poder y autoridad en Castilla.

La referencia de los versos 37-38, entonces, se explicaría solo por la nueva repartición testamentaria que destinaría a Alfonso al trono de Aragón y asignaría a Juan gran parte del patrimonio familiar. También me parece llamativo, en este sentido, que fray Diego describa a Alfonso como ciertamente destinado a un futuro real (v. 32, «amigo, desto non dubdes / ser real la su ventura»), mientras que Juan deberá ser grande en el reino de Castilla (versos 41- 42, «éste faga Dios muy grande / en el reino de Castilla»). Resulta evidente, a mi parecer, que los deseos de fray Diego deben ser puestos en relación con el nuevo diseño político de Fernando, hecho posible por el ascenso de los Trastámara menores al trono aragonés. Sin embargo, el epíteto de «Infante», empleado en los versos 85 y 117 para designar a Fernando, parece una prueba del que él no había sido todavía proclamado rey de Aragón cuando fray Diego compuso el poema, porque era normalmente el título superior el que daba categoría al personaje. $\mathrm{Si}$, como parece, fray Diego compuso este poema en forma de profecía antes del fallo de Caspe, que puso fin al interregno seguido a la muerte de Martín I, reveló buenas cualidades de vidente, tal vez impulsadas por la intención de desear al Infante Fernando el éxito en su pretensión al trono aragonés: para ello el fraile podría tal vez basarse en el peso y legitimidad de los derechos dinásticos que Fernando había recibido de su madre, hija de Pedro IV de Aragón, pero a mi parecer fray Diego no podría haber profetizado tan acertadamente los destinos de Alfonso y de Juan antes de la muerte de Martín I, que tuvo lugar el 31 de mayo de 1410.

En conclusión, examinando con especial atención las referencias históricas, culturales e ideológicas presentes en el panegírico de fray Diego a los hijos de Fernando de Antequera, hemos observado como la estrecha relación entre el texto y su contexto de producción se hace así más claramente visible $\mathrm{y}$, de esta manera, nos ayuda a interpretar y decodificar el mensaje vehiculado por el texto. 


\section{Apéndice}

Este dezir fizo el dicho fray Diego en loor e alabança de los siete fijos que ovo el Rey don Ferrando de Aragón.

Siete planetas reales

vi salir de dos raízes, poderosas e feliçes, todas siete naturales. E las plantas eran tales, segunt fue el mi avisso, que manavan del paraíso de dos fuentes perenales.

E la una se dezía flor de nardo preçïosa,

e la otra abundossa por do el bálsamo corría: estas fuentes que veía eran crïadas de Dios; por virtud d'amas e dos

una verga se regía.

La primera destas plantas que de las fuentes manava alta fuente se llamava por las sus virtudes tantas, que dezir quáles e quántas çiertamente non sabría, pero bien me paresçía salir de raízes santas.

Muy graçiosa crïatura

e de bulto angelical, non crïó mejor nin tal en la su prima natura. Dios la fizo a su figura muy complida de virtudes: amigo, desto non dubdes ser real la su ventura. 
Guarda de Dios verdadera que en todo bien se funda era la planta segunda

desque salió la primera:

Castro traiá por vandera

e señor de los de Lara,

e más fermosa su cara

que la luna en su espera.

Éste faga Dios muy grande

en el reino de Castilla

por que biva sin manzilla,

con los grandes siempre ande,

a qualquier que le demande

sea franco e plazentero,

leal, firme cavallero,

siempre dé e siempre mande.

Santïago glorïosso

ante Dios venga muy presto,

rogando por su Maestro

don Errique preçïoso,

por que sea muy poderoso

a defender ley de Christos,

e los moros sean conquistos

del su nombre temeroso.

Non le puedan contrastar

enemigos de la Ley,

por él tomen nueva ley

en que se puedan salvar:

60

quiéralo Dios ayudar

e el Apóstol Santïago,

por que gane a Cartago

e desí todo Allén Mar.

Por Alcántara regido

el mundo sea muy ancho, sea monarca don Sancho,

Maestre noble e escogido. 
De graçia de Dios complido, así biva en este mundo

por que gane el segundo

a los santos prometido.

Sea su buen guardador

Sant Benito el abat

por que mantenga verdat

a su padre e a su señor.

Otrosí, por su amor, grande la su santa regla, obras faga qu'a Dios plega ensalçarlo en amor.

Como piedra adiamante tal sea la quinta planta por que ponga so su planta a qualquier que se levante contra su padre, el Infante,

de la gente de Ismael

e, segunt diz Danïel, las sus azes les quebrante.

Piedra del monte tajada non por mano humanal mas por graçia divinal, sea firme e bien fundada.

Por él sea reparada la Eglesia de tal guissa que non ande más devissa mas una, bien acordada.

Otras plantas muy preçiosas que salián de la raíz, segunt que la visión diz, fundada entre tales cossas, son las señoras fermosas doña Mariá la mayor, otrosí doña Leonor, que serán muy poderosas. 
Casadas muy altamente

con grandes fijos de reyes, si tú esto assí non vees

di al trobador que miente; en las partes de Oçidente a do nasçen los cristales non nasçieron otras tales nin son vistas de presente.

Dios del çielo radïante, con las sus manos bendichas, estas plantas sobredichas

bendiga muy de talante por que vea el Infante, e la su madre otrosí, muy grant gozo desde aquí por los ver ir adelante.

Recibido: 25/06/2014 Aceptado: 15/9/2014

v. 33 guarda de Dios verdadera] guardelo dios verdadero $m s$ v. 59 por él tomen] por el tomo $m s$

v. 79 obras faga qu'a Dios plega] obras faga a dios plega $m s$ v. 100 fundada] funda $m s$ 


\section{$\cos 8$}

«Siete Planetas Reales»: el diseño Político de Fernando de Antequera EN UNA COMPOSICIÓN DEL CANCIONERO DE BAENA (N. 514, ID 1640)

RESUMEN: El trabajo examina las relaciones que se dibujan entre literatura y poder en la producción poética del franciscano Diego de Valencia de León, autor de un panegírico a los siete hijos de Fernando de Antequera (recogido en el Cancionero de Baena bajo el número 514), que se sitúa en el marco de la literatura de propaganda política e ideológica. A partir del análisis textual se intenta, además, precisar las posibles fechas de redacción del poema.

Palabras clave: Diego de Valencia de León. Cancionero de Baena. Fernando de Antequera. Infantes de Aragón.

«Siete Planetas Reales»: Politic design of Fernando de Antequera In A COMPOSITION OF THE CANCIONERO DE BAENA (N. 514, ID 1640)

ABSTRACT: The paper examines the relationship between literature and power in the poetry of the franciscan Diego de Valencia de Leon, author of a eulogy of the seven children of Fernando de Antequera (Cancionero de Baena, n. 514), which is a clear example of political and ideological propaganda. The possible dates of composition of the poem are also discussed on the basis of textual analysis.

Keywords: Diego de Valencia de León. Cancionero de Baena. Fernando de Antequera. Infantes de Aragón. 